\title{
Preparation of Submicro-porous Nickel Wafers by Molding-Decomposition-Sintering Method Using Nickel Oxalate Nano-Rods as Precursors
}

\author{
Li Tao', Liu Ying ${ }^{2}, \quad$ Ma Guohua ${ }^{3}$
}

${ }^{1}$ Center of Engineering and Technology, Southwest University of Science and Technology, Mianyang 621010, China; ${ }^{2}$ College of Materials Science and Engineering, Sichuan University, Chengdu 610065, China; ${ }^{3}$ Analytical and Testing Center, Southwest University of Science and Technology, Mianyang 621010, China

\begin{abstract}
Submicro-porous nickel wafers were prepared by a molding-decomposition-sintering method, using nickel oxalate nano-rods synthesized via a liquid phase precipitation process as precursors, keeping the decomposition temperature of $360{ }^{\circ} \mathrm{C}$ for 10 min, and sintering temperature of $420,450,480$ and $510{ }^{\circ} \mathrm{C}$ for $10 \mathrm{~min}$, in a tubular oven filled with Ar gas. The study of Infrared spectroscopy (IR) indicates that the as-prepared precursor was pure nickel oxalate. The results of X-ray diffractions (XRD) indicate that the as-treated grey wafers were nickel, which has face-centered cubic crystal structure. The images of scanning electron microscopy (SEM) and atomic force microscopy (AFM) show that the morphology of metal nickel wafers exhibit an obvious porous structure. The structure of pores is irregular with $100 \sim 1000 \mathrm{~nm}$ in diameter, and the pore walls are composed of fiber-like nickel with 100 300 $\mathrm{nm}$ in diameter.
\end{abstract}

Key words: submicro-porous; nickel; molding; decomposition; sintering

Nickel-based porous materials with lager specific surface area and larger electro-catalytic activity ${ }^{[1]}$, are widely used as catalysts ${ }^{[2-5]}$, electrodes ${ }^{[6-9]}$, and magnetic materials ${ }^{[10]}$, etc. Their electrochemical properties are influenced by the porous size, the structure and the distributions which depend on the preparing technology.

Many methods are used for preparing nickel porous materials with different sizes and structure. Using electrochemical deposition method, Zhuo Kai et $\mathrm{al}^{[7]}$ obtained nano-porous Ni-Sn alloy with dendritic structure and 20 50 $\mathrm{nm}$ in pores diameter. Li Jing et al ${ }^{[11]}$ prepared NiTi biological porous materials using the polymer sponge impregnation technique with pore sizes in the range of $150 \sim 500 \mu \mathrm{m}$. D. Chade et $\mathrm{al}^{[12]}$ obtained micro-sized porous Raney nickel adopting atmospheric plasma spraying for alkaline water electrolysers. Li Meng ${ }^{[13]}$ prepared micro-sized porous $\mathrm{Ni}$ bulk catalyst adopting spark plasma sintering (SPS) using spherical atomized $\mathrm{Ni}$ powder as the starting material. Li Kaihua et al ${ }^{[14]}$ prepared foam nickel with $400 \sim 500 \mu \mathrm{m}$ in pore diameter using the method of low temperature electroless plating nickel on the polyurethane foam and thermal decomposition. Zhu Qingwen et $\mathrm{al}^{[10]}$ obtained hollow and porous nickel microspheres adopting low temperature molecular self-assembly in an aqueous medium in which hydrazine hydrate acted as the reducing agent, and the average diameter of the spheres was $1.4 \mathrm{um}$ and mean thickness of the sphere wall was $120 \mathrm{~nm}$. J. H. Choi et al ${ }^{[15]}$ synthesized porous nickel powder with micro-sized pores and reticular structure, using hydrazine monohydrate as reducing agent and polyvinylpyrrolidone (PVP) as a soft template through a polyol process. Liu Zhiguo et $\mathrm{al}^{[16]}$ synthesized nano-

Received date: June 14, 2015

Foundation item: National Natural Science Foundation of China (51002126); Doctoral Fund of Southwest University of Science and Technology (14zx7112) Corresponding author: Li Tao, Ph. D., Associate Professor, Center of Engineering and Technology, Southwest University of Science and Technology, Mianyang 621010, P. R. China, Tel: 0086-816-2419090, E-mail: 1tao74@163.com 
porous nickel rods with $50 \mathrm{~nm}$ in pore diameter, using p-phenylenediamine (PPD) and $\mathrm{NiCl}_{2} \cdot 6 \mathrm{H}_{2} \mathrm{O}$ as reducing agent and oxidizing agent, respectively in aqueous solution. Qi Zhen et al ${ }^{[17]}$ prepared heterogeneous micro-porous $\mathrm{Ni}$ catalysts adopting a de-alloying chemical method, via treating Al-Ni alloys in a $\mathrm{NaOH}$ solution at a temperature of $95 \pm 5^{\circ} \mathrm{C}$. Li Sun et al ${ }^{[18]}$ also prepared heterogeneous submicro-meter sized porous $\mathrm{Ni}$ film using an electrochemical de-alloying method, using $\mathrm{Ni}_{x} \mathrm{Cu}_{1-x}$ alloy film as a precursor.

To date, however, less attention has been paid to the preparation of nano-porous nickel via a process of molding, decomposition and sintering of nickel-organic precursors, while the method of liquid phase precipitation was widely used for preparing nickel-organic precursors ${ }^{[19-21]}$.

In the present work, a simple novel approach was introduced to obtain nano-porous nickel at a low temperature within a relatively short time. Since this method was simple and controllable, it could be used for commercial applications. The effect factors during the process of preparation of porous nickel were analyzed. Subsequently, the phase and the morphology of porous nickel were investigated.

\section{Experiment}

The $\mathrm{NiCl}_{2} \cdot 6 \mathrm{H}_{2} \mathrm{O}$, PVP (polyvinyl pyrrolidone), $\mathrm{NH}_{4} \mathrm{OH}$, and $\mathrm{C}_{2} \mathrm{H}_{6} \mathrm{O}$ were analytically pure regents (AR) which were purchased and used without further purification.

The nickel oxalate precursor was prepared by the method of precipitation and aging process ${ }^{[19]} .0 .2 \mathrm{~g}$ nickel oxalate precursor round wafer was prepared by pressing nickel oxalate powder into the stainless mould, at a pressure of 3 $\mathrm{MPa}$. The nickel oxalate wafer was $16 \mathrm{~mm}$ in diameter. Then, the dried nickel oxalate round wafers were placed into a tubular oven filled with Ar gas, and treated at the temperature of $360{ }^{\circ} \mathrm{C}$ for $10 \mathrm{~min}$. Subsequently, the wafers were treated at the temperature of 420,450 and 480 and $510{ }^{\circ} \mathrm{C}$ for $10 \mathrm{~min}$. Finally, the nickel wafer samples were cooled to room temperature quickly.

The X-ray diffraction (XRD) patterns were recorded by an X'Pert Pro (Holland Philips) using $\mathrm{Cu}$ radiation $(\mathrm{K} \alpha, \lambda=$ $0.15418 \mathrm{~nm}$ ) operating at $40 \mathrm{kV}$ and $40 \mathrm{~mA}$ with $2 \theta$ ranging from $20^{\circ}$ to $80^{\circ}$ and continuous scanning mode. Infrared (IR) was recorded on a Nicolet 5700 spectrometer in the range of $4000-400 \mathrm{~cm}^{-1}$ using $\mathrm{KBr}$ pellets method. The scanning electron microscope (SEM) images were taken with an Ultra 55 (German ZEISS) field-emission scanning electron microscope. The atomic force microscopy (AFM) images were taken with a SPA300HV (Japan SEIKO). The thermogravimetry analyzer and derivative thermogravimetry (TGA-DTG) curves were recorded by a SDT Q600 (America TA) thermal analyzer, at heating rate of $20^{\circ} \mathrm{C} / \mathrm{min}$ in $\mathrm{Ar}$ gas atmosphere.

\section{Results and Discussion}

\subsection{Characteristics of nickel oxalate nano-rods}

Fig. 1 shows the IR pattern of as-prepared powder, which indicates that the band at $3400 \mathrm{~cm}^{-1}$ corresponds to the stretching vibrations of the hydroxyl groups of $\mathrm{H}_{2} \mathrm{O}$. The most intensive band at $1625 \mathrm{~cm}^{-1}$ is due to the anti-symmetric stretching vibration absorption of $v_{\text {a }}$ $(\mathrm{C}=\mathrm{O}-\mathrm{C})$, indicating the presence of carbonyl groups. The bands of 1315 and $1360 \mathrm{~cm}^{-1}$, in the area of $1300 \sim 1420 \mathrm{~cm}^{-1}$ are due to the symmetric stretching vibration absorption of $v_{\mathrm{s}}(\mathrm{C}=\mathrm{O}-\mathrm{C})$. The band of $810 \mathrm{~cm}^{-1}$ is due to the stretching vibration absorption of $v_{\mathrm{s}}(\mathrm{O}-\mathrm{C})$. The band of $490 \mathrm{~cm}^{-1}$ is due to the stretching vibration absorption of $v(\mathrm{O}-\mathrm{Ni})^{[20]}$. IR pattern further indicates that the powder is nickel oxalate hydrate which corresponds to the SDBS card No.17149.

Fig. 2 shows the SEM image of as-prepared nickel oxalate nano-rods. The image shows clearly that the powder consists of a large quantity of uniform, well-separated and nano-sized rods with 100 200 $\mathrm{nm}$ in diameter, and 1.0 5.0 $\mu \mathrm{m}$ in length, and the surface is a little rough.

Fig. 3 shows the TGA-DTG curves of as-prepared nickel oxalate nano-rods. DTG curve shows that there is a weak endothermic peak at about $68^{\circ} \mathrm{C}$ which corresponds to the elimination of adsorptive water and ammonia molecules. In

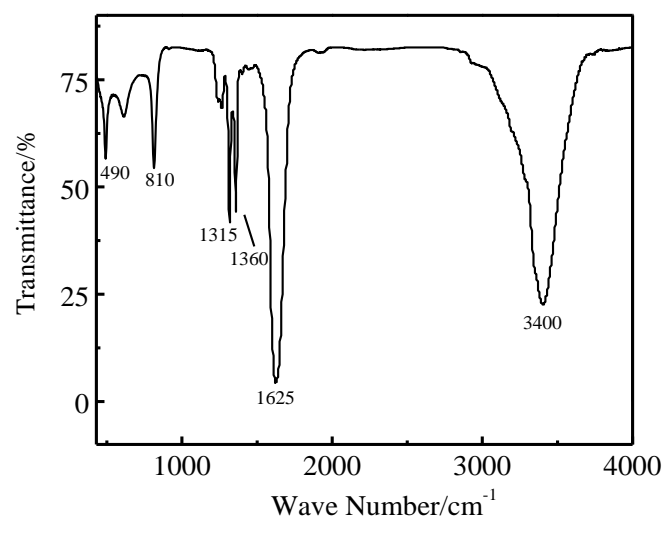

Fig.1 IR pattern of nickel oxalate nano-rods

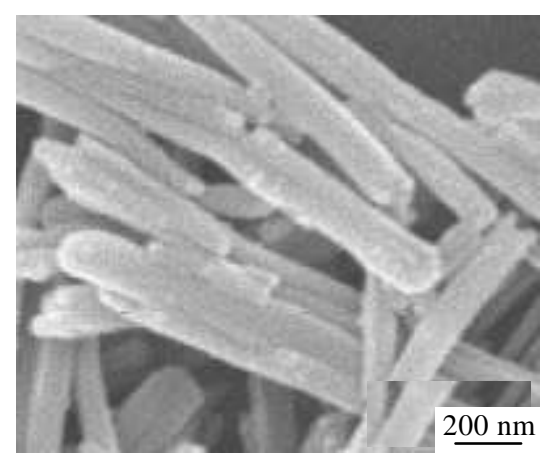

Fig.2 SEM image of nickel oxalate nano-rods 
the range from $120{ }^{\circ} \mathrm{C}$ to $260{ }^{\circ} \mathrm{C}$, there is a weak endothermic peak at about $200{ }^{\circ} \mathrm{C}$, which corresponds to the elimination of crystal water molecules. In the range from $260{ }^{\circ} \mathrm{C}$ to $400{ }^{\circ} \mathrm{C}$, there is a strong endothermic peak at $370{ }^{\circ} \mathrm{C}$, which corresponds to the decomposition process of nickel oxalate.

\subsection{Characteristics of submicro-porous nickel}

Fig.4 shows the XRD patterns of submicro-porous nickel prepared at the temperatures of $420,450,480$ and $510{ }^{\circ} \mathrm{C}$. XRD patterns show that the shapes of four patterns are almost same, and the three significant diffraction peaks are located at about $44.59^{\circ}, 51.99^{\circ}$, and $76.52^{\circ}$, which correspond to the (111), (200), and (220) crystal planes of nickel, respectively. The crystal parameters indicate that the as- prepared nickel crystal belongs to face-centered cubic geometry (JCPDS: 04-0850). The strongest diffraction peak (111) implies that the crystal growth direction of nickel seed is favorably oriented parallel to the [111] direction.

Fig.5 shows the SEM images of submicro-porous nickel prepared at the temperatures of $420,450,480$ and $510{ }^{\circ} \mathrm{C}$. The images show clearly that the as-prepared wafer samples all have porous structure with $100 \sim 1000 \mathrm{~nm}$ in pore diameter. Fig.5a shows that at the temperature of

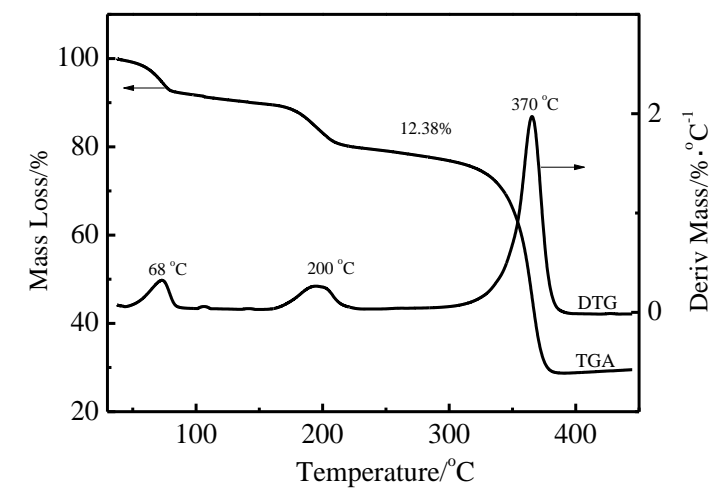

Fig.3 TGA-DTG curves of nickel oxalate nano-rods

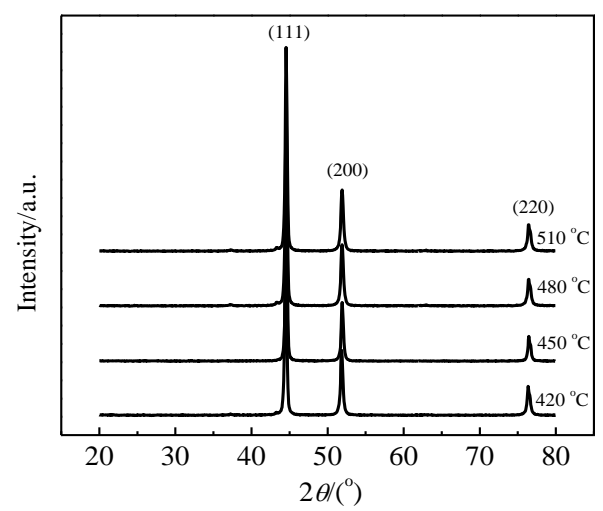

Fig.4 XRD patterns of submicro-porous nickel wafers prepared at different temperatures

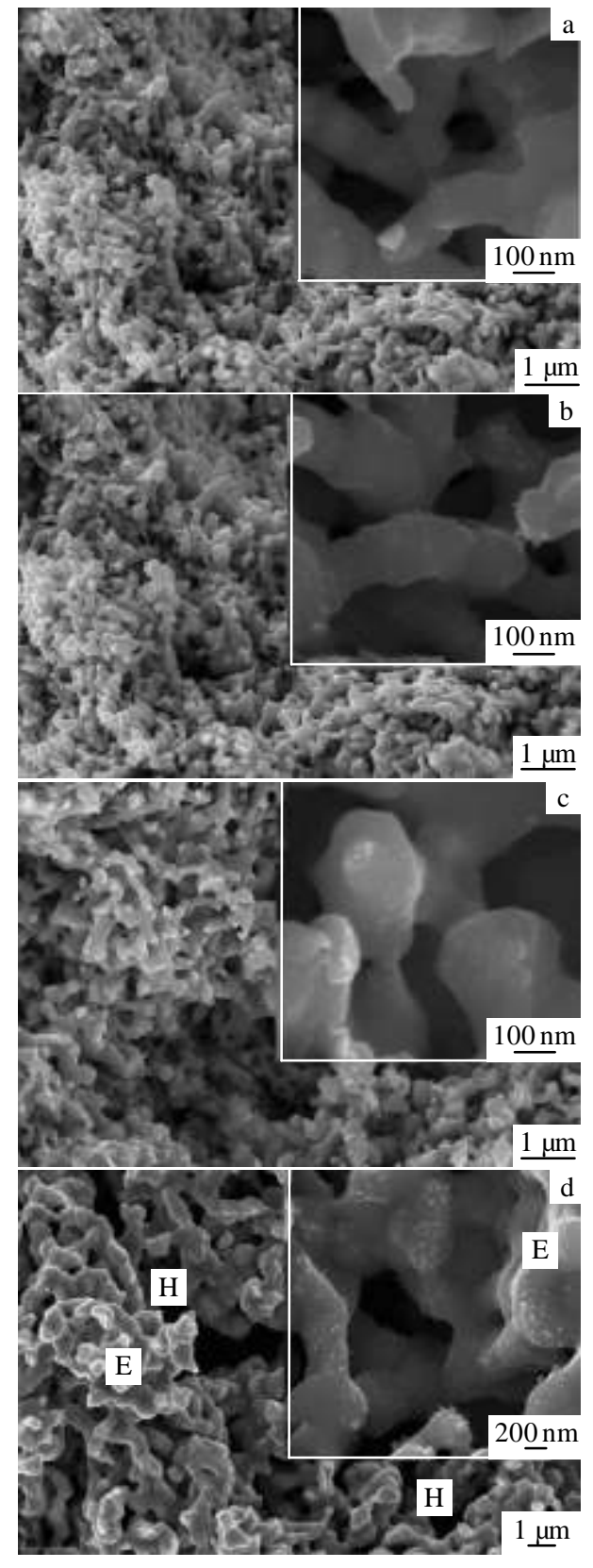

Fig.5 SEM images of submicro-porous nickel prepared at different temperatures: (a) $420{ }^{\circ} \mathrm{C}$, (b) $450{ }^{\circ} \mathrm{C}$, (c) $480{ }^{\circ} \mathrm{C}$, and (d) $510{ }^{\circ} \mathrm{C}$

$420{ }^{\circ} \mathrm{C}$, the nickel nano-rods interweave together; at the same time, the pores and walls are formed. In a small window set in Fig.5a, the walls of pores also clearly exhibit fiber-like shape, and the hollows show very irregular space. Fig.5b also reveals a porous structure. However, the fiber-like walls of pores become thicker and shorter which are shown in the small window. At the same time, the hollows change from very irregular space to long-round shape pores. Fig.5c also shows a porous structure. However, the nickel fibers are melted obviously, which become much 
more thick and short, and the shapes of fibers nearly disappear. Fig.5d shows the porous structure with larger pores and hollows, but the nickel fibers are melted badly, and the formation of nickel blocks happens seriously as marked with letter E. As a result, the walls of pores become the thickest, much pores disappear, and much hollow and crack come into being as marked with letter $\mathrm{H}$.

Fig.6 shows the AFM images of submicro-porous nickel prepared at the temperatures of 480 and $510{ }^{\circ} \mathrm{C}$. Fig.6a indicates that the nickel surface is rough, and the pore shape is long-round. Fig.6b reveals that the nickel surface is relatively smooth, and the shapes of pores become nearly round. Fig.5 and Fig.6 indicate that in the process of melting and shrinking along with temperature increase, most pores change from long-round shape to nearly round shape.

\subsection{Mechanism}

The formation process of submicro-porous nickel wafers by the molding-decomposition-sintering method using nickel oxalate nano-rods as precursors includes three steps: first step, the nickel oxalate wafers are obtained by molding process, at the same time, a great deal of small pores are also formed. Second step, with the oxalate nickel nano-rods decomposition, the gases of $\mathrm{CO}_{2}$ and $\mathrm{H}_{2} \mathrm{O}$ are produced and removed, then the nickel nano-fibers are formed, and many space and big pores are formed. At the same time, and the

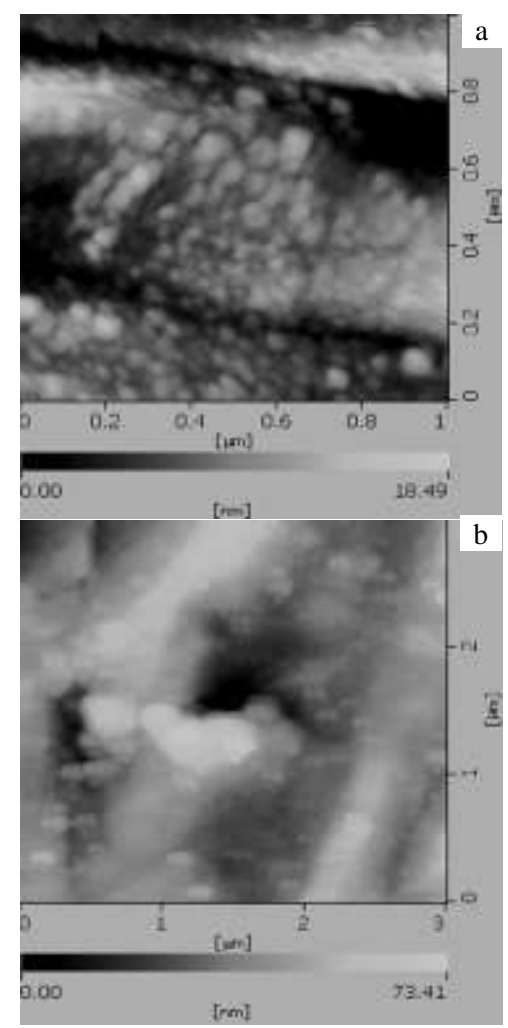

Fig.6 AFM images of submicro-porous nickel prepared at the temperatures of $480{ }^{\circ} \mathrm{C}$ (a) and $510{ }^{\circ} \mathrm{C}(\mathrm{b})$ volume of wafers become smaller and harder. Third step, with the increase of temperature, the surface of nickel nano-fibers begin melting and bonding to each other. So, nickel fibers become shorter and thicker; at the same time, the space and pores become smaller, and many nickel block are also formed. Finally, the wafers become very hard, and the volume shrinks very seriously.

\section{Conclusions}

1) Molding process is very important for preparing nickel oxalate wafers and nickel wafers. Nickel oxalate precursor wafers with $16 \mathrm{~mm}$ in diameter, can be prepared by pressing nickel oxalate powder in a stainless mould, at a pressure of $3 \mathrm{MPa}$.

2) Submicro-porous nickel wafers can be obtained at the temperatures of $420,450,480$ and $510{ }^{\circ} \mathrm{C}$, in a tubular oven filled with $\mathrm{Ar}$ gas. The pore structure is irregular with $100 \sim 1000 \mathrm{~nm}$ in diameter.

\section{References}

1 Xie Zhengwei, He Ping, Du Licheng et al. Electrochim Acta[J], 2013, 88: 390

2 Kirillov V A, Fedorova Z A, Danilova M M et al. Appl Catal $A[\mathrm{~J}], 2011,401: 170$

3 Danilova M M, Fedorova Z A, Zaikovskii V I et al. Appl Catal $B[\mathrm{~J}], 2014,147: 858$

4 Fukuhara C, Hyodo R, Yamamoto K et al. Appl Catal A[J], 2013, 468: 18

5 Lua A C, Wang H Y. Appl Catal B[J], 2013, 132: 469

6 Wang Jun, You Jia, Li Zhanshuang et al. J Electroanal Chem[J], 2008, 624: 241

7 Zhuo Kai, Jeong M G, Chung C H. J Power Sources[J], 2013, 244: 601

8 Yan Xiaoyan, Tong Xili, Wang Jian et al. Mater Lett[J], 2013, 106: 250

9 Escuderoa M J, Rodrigob T, Mendozac L et al. J Power Sources[J], 2005, 140: 81

10 Zhu Qingwei, Zhang Yihe, Wang Jiajun et al. Solid State Sci[J], 2011, 13: 438

11 Li Jing, Yang Hailin, Ruan Jianming et al. Rare Metal Mater Eng[J], 2013, 42(5): 1023 (in Chinese)

12 Chade D, Berlouis L, Infield D et al. Int J Hydrogen Energy[J], 2013, 38: 14380

13 Li Meng. Rare Metal Mater Eng[J], 2010, 39(7): 1858 (in Chinese)

14 Li Kaihua, Luo Jiangshan, Liu Ying, et al. High Power Laser Particle Beams[J], 2007, 19: 1158 (in Chinese)

15 Choi J H, Kim D H, Yoon J C et al. J Alloy Compd[J], 2009, 487: L8

16 Liu Zhiguo, Zu Yuangang, Guo Songlin et al. Mater Sci Eng $C[\mathrm{~J}], 2008,28: 1284$

17 Qi Zhen, Zhang Zhonghua, Jia Haoling et al. J Alloy Compd [J], 2009, 472: 71 
18 Sun Li, Chien C L, Searson P C. Chem Mater[J], 2004, 16: 3125

19 Li Tao, Liu Ying, Peng Tongjiang et al. J Wuhan Univ Techn-Mater Sci Ed[J], 2011, 26: 1041
20 Li Tao, Liu Ying, He Dengliang et al. Rare Metal Mater Eng[J], 2012, 41(9): 1527 (in Chinese)

21 Li Tao, Liu Ying, Li Jun et al. Rare Metal Mater Eng[J], 2012, 41(5): 753 (in Chinese)

\title{
草酸镍纳米棒成型-分解-烧结制备亚微米多孔镍薄片
}

\author{
李 涛 $^{1}$, 刘 颖 $^{2}$, 马国华 ${ }^{3}$
}

(1. 西南科技大学工程技术中心, 四川 绵阳 621010)

(2. 四川大学材料科学与工程学院, 四川 成都 610065)

(3. 西南科技大学分析测试中心, 四川 绵阳 621010)

摘 要: 以离子液相沉淀技术制备的草酸镍纳米棒为前驱体, 采用成型-分解-烧结技术, 在氩气气氛炉中, 于 $360{ }^{\circ} \mathrm{C}$ 温度分解反应 $10 \mathrm{~min}$, 然后分别于 $420,450,480$ 和 $510{ }^{\circ} \mathrm{C}$ 温度条件下烧结反应 $10 \mathrm{~min}$, 制备出具有亚微米级尺寸多孔结构的金属镍薄片。红外光谱分析表明前 驱体为较纯的草酸镍粉体, X射线衍射谱分析表明制备的多孔镍薄片样品具有面心立方晶体结构, 扫描电子显微镜和原子力显微镜分析 表明金属镍薄片样品显现出烧结状的多孔结构, 孔结构不规则、不均匀, 孔洞尺寸范围为100 1000 nm, 孔壁是由直径100 300 nm的纤 维状金属镍构成。

关键词: 纳米多孔; 镍片; 成型; 分解; 烧结

作者简介: 李 涛, 男, 1974 年生, 博士, 副教授, 西南科技大学工程技术中心, 四川 绵阳 621010, 电话: 0816-2419090, E-mail: 1tao74@163.com 